\title{
Análise da composição gravimétrica dos resíduos sólidos gerados na Ilha de Cotijuba em Belém - PA
}

Gravimetric composition analysis of solid waste generated in Cotijuba Island in Belém - PA

Análisis de la composición gravimétrica de los residuos sólidos generados en la isla de Cotijuba en

Belém - PA

Luciane Gomes Fiel

ORCID: https://orcid.org/0000-0002-9788-2331 Universidade Federal do Pará, Brasil

E-mail: lucianefiel@gmail.com

Albertino Monteiro Neto

ORCID: https://orcid.org/0000-0001-7318-2413

Universidade Federal Rural da Amazônia, Brasil

E-mail: albertino.monteiro.neto@gmail.com

Marina Costa de Sousa

ORCID: https://orcid.org/0000-0002-9063-6496

Universidade Federal do Pará, Brasil

E-mail: marina.eaer@gmail.com

Mônica Trindade Abreu de Gusmão

ORCID: https://orcid.org/0000-0002-0828-9991

Universidade Federal Rural da Amazônia, Brasil E-mail: monica.gusmao@ufra.edu.br

Paula Fernanda Pinheiro Ribeiro Paiva

ORCID: https://orcid.org/0000-0001-8458-3132

Universidade Federal Rural da Amazônia, Brasil E-mail: engpaulapinheiro@gmail..com

Thais Gleice Martins Braga

ORCID: https://orcid.org/0000-0001-9559-7142

Universidade Federal Rural da Amazônia, Brasil E-mail: thais.braga@ufra.edu.br

Orleno Marques da Silva Junior ORCID: https://orcid.org/0000-0002-1173-1429 Universidade Federal do Amapá, Brasil E-mail: orlenomarques@yahoo.com..br

Maria de Lourdes Pinheiro Ruivo ORCID: https://orcid.org/0000-0002-6222-5534 Museu Paraense Emilio Goeldi, Brasil E-mail: ruivo@museu-goeldi.br

\begin{abstract}
Resumo
Diante do atual cenário da gestão dos resíduos sólidos no Brasil, faz-se necessário além do diagnóstico da geração, a composição desses resíduos, para que o planejamento e a formulação de estratégias sejam mais eficientes e estejam alinhadas com os preceitos da Política Nacional dos Resíduos sólidos (PNRS).Desse modo,este trabalho teve como objetivos caracterizar os resíduos sólidos gerados na Ilha de Cotijuba, identificar os resíduos recicláveis comercializados, realizar comparação desses resíduos em contexto nacional e avaliar as condições de trabalho dos catadores de recicláveis que atuam na Ilha, por meio de entrevistas, realizadas de forma direta e semiestruturada, assim como, da quantificação e caracterização dos resíduos, através da análise gravimétrica, composta por três etapas: quarteamento, identificação e pesagem das categorias de resíduos. De posse dos dados de composição gravimétrica, constatou-se que a dinâmica de disposição dos tipos de resíduos presentes na Ilha de Cotijuba obedecem à tendência nacional, e somente para a categoria papel e papelão houve uma diferença notável. Sendo as misturascom residuos orgânicos, o fator que mais inviabilizaa reciclagem dos resíduos, que por sua vez, tornam-se rejeitos. Assim, nota-se a importância da coleta seletiva, como alternativapara a solução de parte do problema da destinação adequada dos resíduos sólidos urbanos, por possibilitar o melhor reaproveitamento dos materiais recicláveis e da matéria orgânica para a comunidade local. Somado a isso, são necessáriasações de educação ambiental da comunidade local, treinamento dos cooperados e política de gestão de resíduos sólidos adaptadas a realidade da Ilha.
\end{abstract}

Palavras-chave: Geração de RSU; Gravimetria; Coleta seletiva. 


\begin{abstract}
Given the current background of solid waste management in Brazil, it is necessary, in addition to the diagnosis of generation, the composition of these wastes, so that the planning and formulation of strategies are more effective and in line with the precepts of the National Policy of Solid Waste (NPSW). Thus, this study aimed to characterize the solid waste generated in the Island of Cotijuba, identify the recyclable waste that is sold, compare these wastes with a national context, and evaluate the working conditions of recyclable collectors who work on the Island, through interviews , carried out in a direct and semi-structured way, as well as the quantification and characterization of waste, through gravimetric analysis, consisting of three steps: quartering, identification and weighing of waste categories. With the gravimetric composition data, it was found that the dynamics of disposal of the types of waste present on the island of Cotijuba follow the national trend, and only for the paper and cardboard category there was a notable difference. Being the blend with organic waste, the factor that makes the recycling of waste unfeasible, which in turn, becomes waste. Thus, the importance of selective collection was realized as an alternative to solving part of the problem of proper disposal of urban solid waste (USW), as it enables better reuse of recyclable materials and organic matter for the local community. Added to this, environmental education actions for the local community, training of cooperative members, and a solid waste management policy adapted to the reality of the Island are necessary.
\end{abstract}

Keywords: USW generation; Gravity; Selective collect.

\title{
Resumen
}

Dado el escenario actual de la gestión de residuos sólidos en Brasil, es necesario, además del diagnóstico de generación, la composición de estos residuos, para que la planificación y formulación de estrategias sea más eficiente y acorde con los preceptos de la Políticas Nacionale de Resíduos de sólidos (PNRS). Así, este estudio tuvo como objetivo caracterizar los residuos sólidos generados en la Isla de Cotijuba, identificar los residuos reciclables vendidos, comparar estos residuos en un contexto nacional y evaluar las condiciones de trabajo de los recolectores de reciclables que laboran en la Isla, a través de entrevistas, realizadas en de forma directa y semiestructurada, así como la cuantificación y caracterización de residuos, mediante análisis gravimétrico, que consta de tres pasos: despiece, identificación y pesaje de categorías de residuos. Con los datos de composición gravimétrica, se encontró que la dinámica de disposición de los tipos de residuos presentes en la isla de Cotijuba sigue la tendencia nacional, y solo para la categoría de papel y cartón hubo una diferencia notable. Siendo las mezclas con residuos orgánicos, el factor que hace inviable el reciclaje de residuos, que a su vez, se convierten en rechazos. Así, se destaca la importancia de la recogida selectiva, como alternativa a solucionar parte del problema de la correcta disposición de los residuos sólidos urbanos, ya que permite una mejor reutilización de materiales reciclables y materia orgánica para la comunidad local. Sumado a esto, son necesarias acciones de educación ambiental para la comunidad local, capacitación de los cooperativistas y una política de manejo de residuos sólidos adaptada a la realidad de la isla.

Palabras clave: Generación de RSU; Gravedad; Recogida selective.

\section{Introdução}

É natural que com o crescimento populacional haja o aumento da quantidade de resíduos gerados, mas somado a isso, estão as mudanças de hábitos da população, que são produtos do modelo de produção e consumo adotados (Barbosa \& Gonçalves, 2018). Assim, gerenciar a grande quantidade de resíduos sólidos produzidos diariamente nos municípios brasileiros, tornou-se uma problemática para os administradores públicos, os quais precisam viabilizar programas que englobam todas as etapas entre geração, segregação até a destinação final (Franco, 2012).

Nesse sentido, o conhecimento da geração e da composição dos resíduos sólidos é de fundamental importância para o planejamento de todas as ações voltadas para todos os aspectos da gestão dos resíduos (Barbosa \& Gonçalves, 2018). O Gerenciamento de resíduos sólidos indica que a partir do conhecimento das características dos resíduos são viabilizadas condições de aproveitamento, que uma vez implantadas, tem impactos diretos na redução dos gastos com coleta, transporte e disposição final, aumentando a vida útil dos aterros sanitários e reduzindo os custos com o tratamento do passivo ambiental. Atrelado a isso, ainda há geração de emprego e renda, em função da comercialização dos materiais recicláveis no mercado.

A coleta seletiva é um dos instrumentos da Política Nacional de Resíduos Sólidos (PNRS), que funciona como um mecanismo essencial para se atingir a meta de disposição final ambientalmente adequada (Casais et al., 2020). No Brasil, a coleta seletiva é realizada majoritariamente por meio dos catadores, que estão na linha de frente da reciclagem (Meireles, 2019). Entre os inúmeros benefícios trazidos, a coleta seletiva também é uma oportunidade de fonte de renda e trabalho para os catadores de materiais recicláveis (Fontão, 2021). 
Dessa forma, a Lei 12.305/2010 surge para definir estratégias que viabilizem a agregação de valor aos resíduos. Ao mesmo tempo, visa propiciar a inclusão social e estabelecer o papel dos Estados e Municípios na gestão dos resíduos sólidos, bem como direcionar as condições de acesso a fontes de recursos federais (Brasil, 2010).

Embora as Políticas Públicas existam no campo teórico, elas dependem da gestão pública para serem executadas. No aspecto da dimensão política, os instrumentos que a Ilha de Cotijuba dispõe e que fazem referência ao gerenciamento de Resíduos Sólidos são a PNRS e a Lei n 11.445 de 2007. Embora seja possível, percebe-se que alguns aspectos não são incorporados em sua totalidade na Ilha, como a intersetorialidade, integridade dos serviços de saneamento e a não vigência de um Plano Municipal de Gestão Integrada de Resíduos Sólidos - PMGIRS, o qual está em processo de conclusão (Rodrigues et al., 2020).

Evidencia-se tal problemática devido à ausência de comprometimento do governo com a população e o meio ambiente, refletido no descarte irregular do lixo, geralmente provocado pela própria população e visitantes, o que gera malefícios para o ambiente e para a saúde de quem reside no local (Santos et al., 2017).

Nesse sentido, a análise gravimétrica surge como um instrumento auxiliador na elaboração de planos de gerenciamento, os quais objetivam a minimização da quantidade gerada de resíduo, considerando o atendimento das necessidades sociais e buscando a sustentabilidade do sistema (Gouvea, 2012). Esses dados são fundamentais na elaboração de propostas e soluções eficazes, visto que através da análise gravimétrica dos resíduos que se obtém as quantidades e qualidades dos resíduos avaliados (Menezes et al., 2016). Somado a isso, deve-se avaliar a situação do município quanto à execução do plano de gerenciamento de resíduos sólidos e, principalmente, o nível de conscientização e participação efetiva da comunidade no processo (Gasques, 2013).

Dado o exposto, este trabalho teve como objetivos caracterizar os resíduos sólidos gerados na Ilha de Cotijuba, identificar os resíduos recicláveis comercializados por meio da análise da composição gravimétrica e, realizar comparação desses resíduos em contexto nacional, assim como, avaliar as condições de trabalho dos catadores de recicláveis que atuam na ilha.

\section{Metodologia}

\subsection{Caracterização da Área}

A Ilha de Cotijuba faz parte das 39 ilhas da capital paraense, localiza-se na confluência da Baía de Marajó com a Baía de Guajará, no estado do Pará (Pereira, 2019), nas coordenadas 1¹4'51.44”'S e 48³2’47.14" (Figura 1), dista 9km do distrito de Icoaraci e $33 \mathrm{~km}$ do centro de Belém (Brilho, 2015). 
Figura 1: Localização da Ilha de Cotijuba.

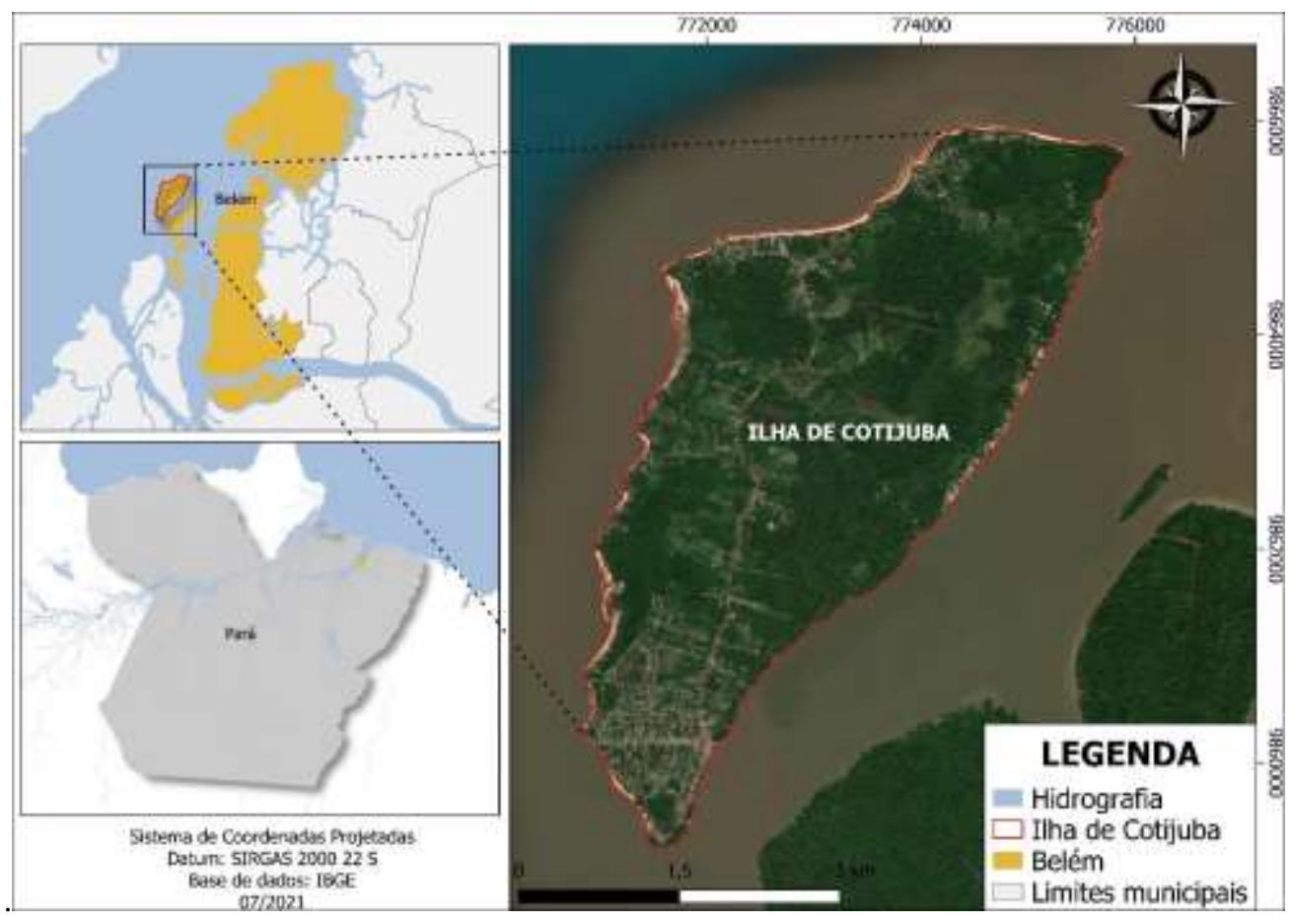

Fonte: Autores (2021).

A Ilha tem população estimada de 9 mil habitantes e ocupa uma área de aproximadamente 16 hectares com uma costa abrangendo $15 \mathrm{~km}$ de praias de água doce (Belém, 1999). Possui vegetação de mangue, clima quente e úmido, e apresenta alteração da cobertura vegetal associada à ocupação urbana crescente e desordenada e à pressão humana sobre os remanescentes florestais (Belém, 1999). Na parte sul da ilha se concentra a maior densidade populacional, este fato culmina do histórico da ocupação da ilha pela organização do espaço próximo ao terminal hidroviário (Melo, 2010). A Ilha contém equipamentos urbanos, e ainda conserva forte característica rural. Tem acesso exclusivamente fluvial, cuja a frequência de embarcações é diária e regulamentada pela Secretaria de Mobilidade Urbana de Belém - SEMOB.

A economia local é comumente oriunda da pesca, principalmente a do camarão (Macrobrachium jelskii), atividade importante para a manutenção das famílias, pois se destina unicamente ao consumo destas (Melo, 2010), como também da agricultura e do extrativismo devido à riquíssima diversidade de fauna e flora, que contribuem com o perfil socioeconômico da Ilha. Por ser próxima da capital, Cotijuba se tornou um grande atrativo turístico, devido a contribuição das manifestações religiosas, do comércio e das prestações de serviço de transporte fluvial e terrestre (Melo, 2010).

Dados da Companhia de Transportes de Belém - CTBEL (2005) registraram 17 mil visitantes ao mês fora da alta temporada e 50 mil passageiros só no mês de Julho totalizando 240 mil ao ano, ressalta-se que esses registros referem-se aos passageiros que utilizam o transporte oferecido pela prefeitura de Belém, não sendo computadas as viagens em barcos de terceiros ou particulares, com isso supõe-se que a estimativa real ultrapasse os dados oficiais caracterizando o turismo de massa (Huffner \& Bello, 2013).

\subsection{Impactos na Ilha}

Para Mesquita e Silva (2010), a intensa e acelerada ocupação humana da Ilha de Cotijuba nos últimos anos se apresentou como resultado do crescimento do uso turístico do seu território, o que tem causado forte pressão ambiental, exercida não somente pelos visitantes, mas também pelos que já residem na ilha que se apropriam do espaço de forma impactante. 
O turismo em Cotijuba apresenta-se potencialmente degradante e poluidor, tendo em vista que se trata de uma área de preservação ambiental, onde sua ocupação e atividades inseridas deveriam estar em consonância com um plano de manejo préconcebido, além de diversos outros aspectos voltados a sustentabilidade ambiental (Huffner \& Bello, 2011).

$\mathrm{Na}$ ilha, são identificados alguns impactos ambientais negativos provocados pelas atividades turísticas nos atrativos naturais tais como: acúmulo de resíduos sólidos, poluição sonora, o aumento de dejetos nos rios e praias, e a degradação ambiental com o desmatamento da floresta primária (PARATUR, 2011). Identificou-se o acúmulo de resíduos em áreas de grande potencial turístico como o Mercado Ver-o-Peso, nos portos fluviais, nas ilhas e nas margens dos rios é um fato que pode comprometer de forma negativa as atividades turísticas na região.

De acordo com dados da BELÉMTUR (2008), nos períodos de férias escolares e feriados a ilha chega a receber cerca de 20.000 visitantes por fim de semana. Em 2016, o Diário do Turismo (2016) informou que Cotijuba recebeu mais de 150 mil visitantes em feriados prolongados.

\subsection{Etapas Metodológicas}

A pesquisa desenvolvida apresenta caráter exploratório, descritivo e quantitativo (Pereira et al., 2018). Para isso, utilizou-se de métodos de coleta de informações como sugere Freitas (2013). Deste modo, a pesquisa foi organizada em duas fases. A primeira referiu-se à fase de entrevistas, onde foram realizadas de forma direta e semiestruturada, conforme recomenda Kauark, Manhães e Medeiros (2010). Já a segunda fase foi relativa à quantificação e caracterização dos resíduos, a qual foi realizada por meio da análise gravimétrica como sugere a literatura (Moura et al., 2012, Rezende et al., 2013 \& Lima et al., 2018). E por fim, a composição gravimétrica dos resíduos sólidos urbanos que chegam no ponto de triagem da Cooperativa Escajuba na Ilha, a análise foi dividida em três etapas:

$1^{\circ}$ Etapa: aplicou-se o método do quarteamento de amostras de resíduos sólidos orgânicos e inorgânicos. Na qual dois tambores de capacidade de 180 litros (L) (Figura 2a) foram despejados sob uma lona (Figura 2b) e misturados a fim de homogeneizar a amostra. No momento do quarteamento dos resíduos sólidos, foram utilizados os seguintes equipamentos de proteção individual: máscara cirúrgica, luvas amarelas de borracha de cano longo e sapatos fechados.

Figura 2: (a) Materiais coletados e armazenados nos tambores; (b) Materiais sendo separados para posterior pesagem.

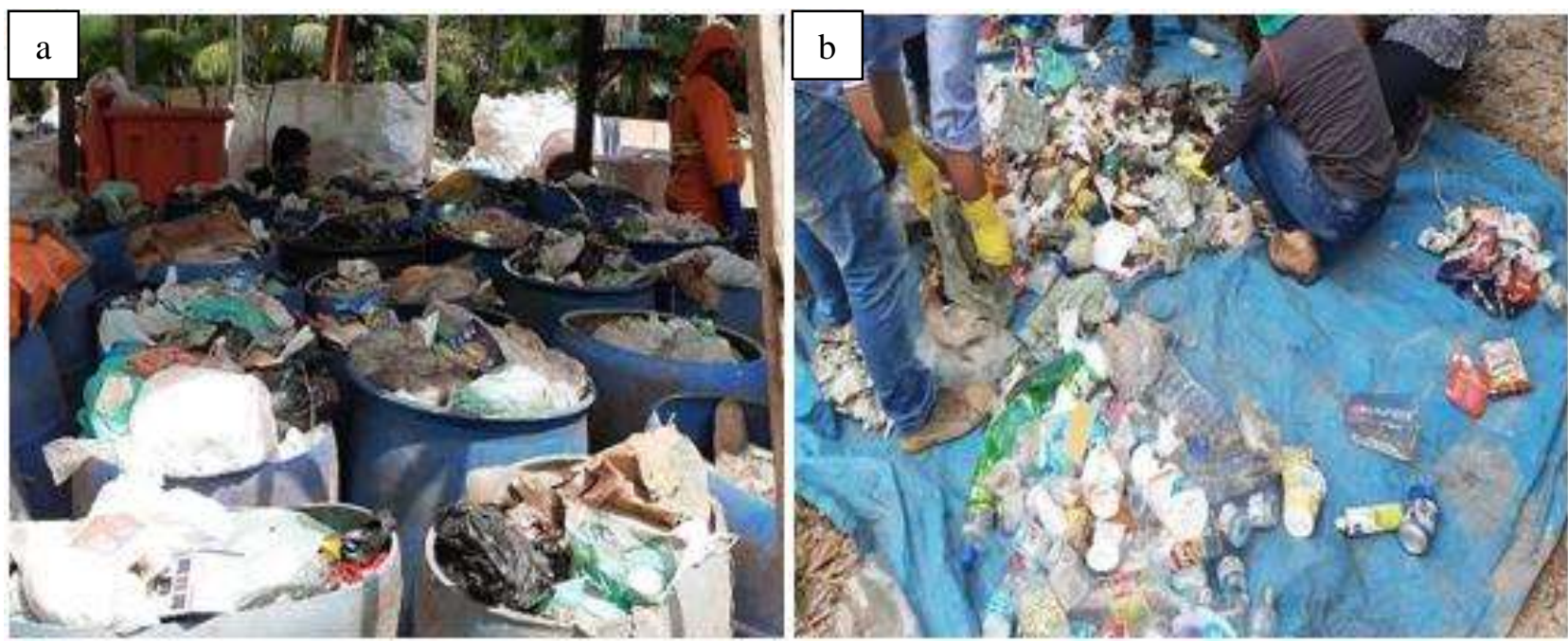

Fonte: Autores (2019).

$2^{\circ}$ Etapa: realizou-se a interpretação dos dados obtidos por meio da gravimetria aplicada sobre os resíduos sólidos. As amostras selecionadas foram ensacadas e pesadas com auxílio de uma balança digital de gancho (Figura 3), cada uma delas 
separadamente. Em seguida foram espalhados sobre uma lona e separados por tipo de resíduos sendo identificados: Plástico mole/sacos, papel/papelão, plástico geral, contaminantes, tecido, vidro, alumínio, material orgânico, dentre outros.

Figura 3: Material separado sendo pesado com a balança digital.

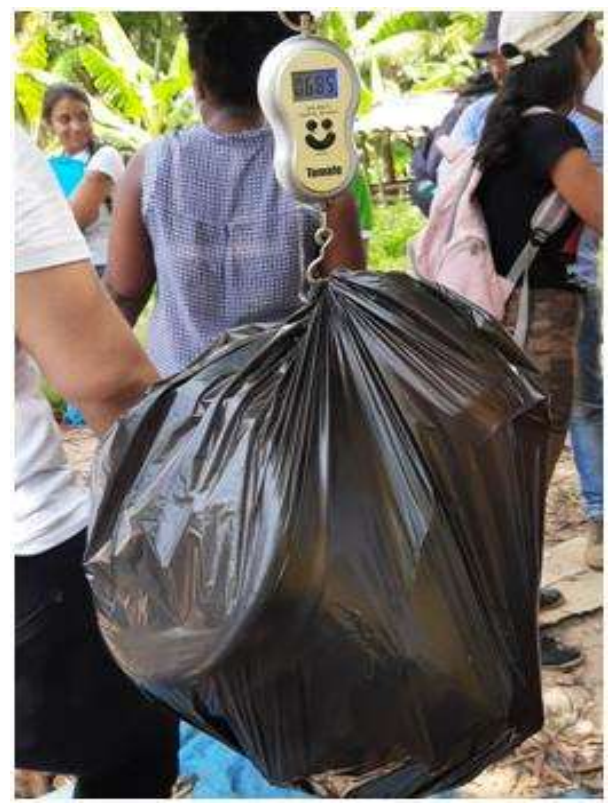

Fonte: Autores (2019).

$3^{\circ}$ Etapa: Em seguida, calculou-se a porcentagem de cada parcela de material em relação ao peso total da amostra, obtendo-se, assim, a porcentagem de cada classe de resíduo separado, como pode ser observado nas Figuras 4, 5 e 6.

Figura 4: (a) Plástico em geral; (b) Plástico mole/sacos.

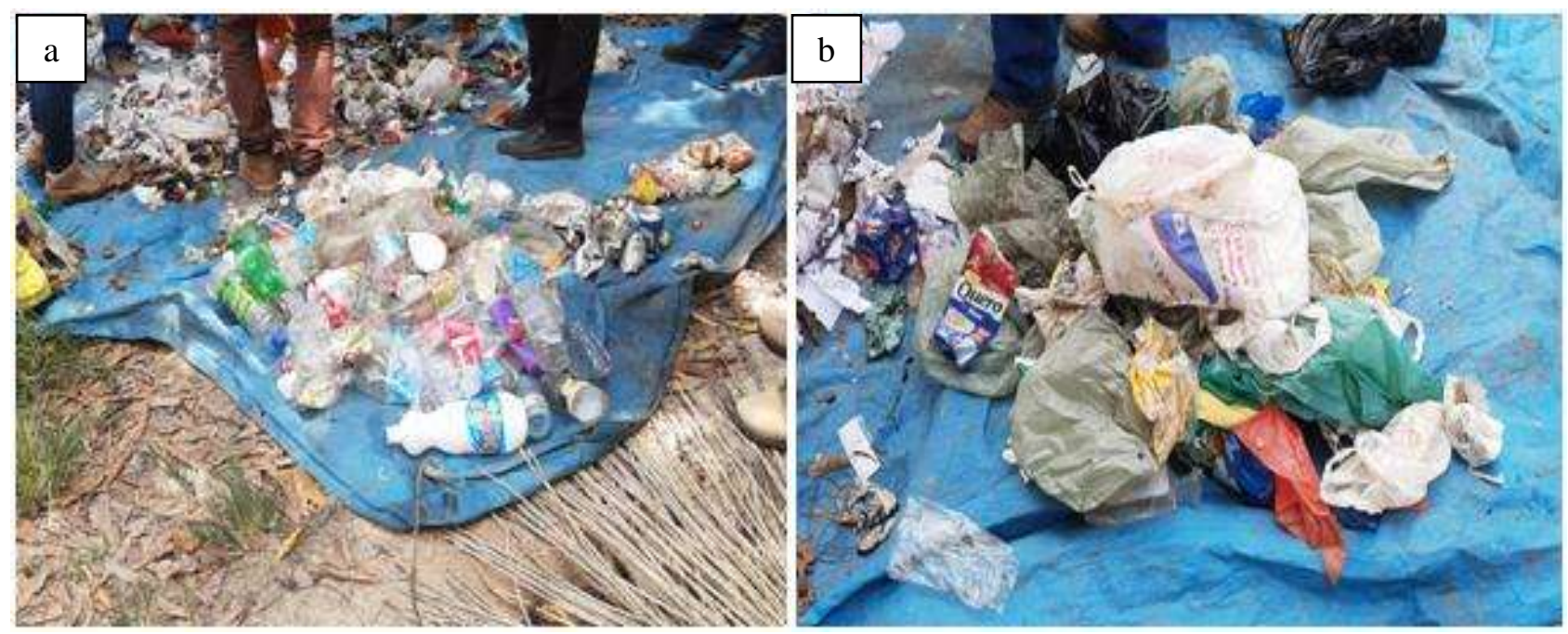

Fonte: Autores (2019).

A Figura 4a demonstra a predominância de garrafas pet e garrafas de detergente na categoria de plásticos gerais. Já na Figura 4b, predominaram as sacolas plásticas de supermercados e sacos de embalagens e produtos. 
Figura 5: Vidros, roupas e sapatos.

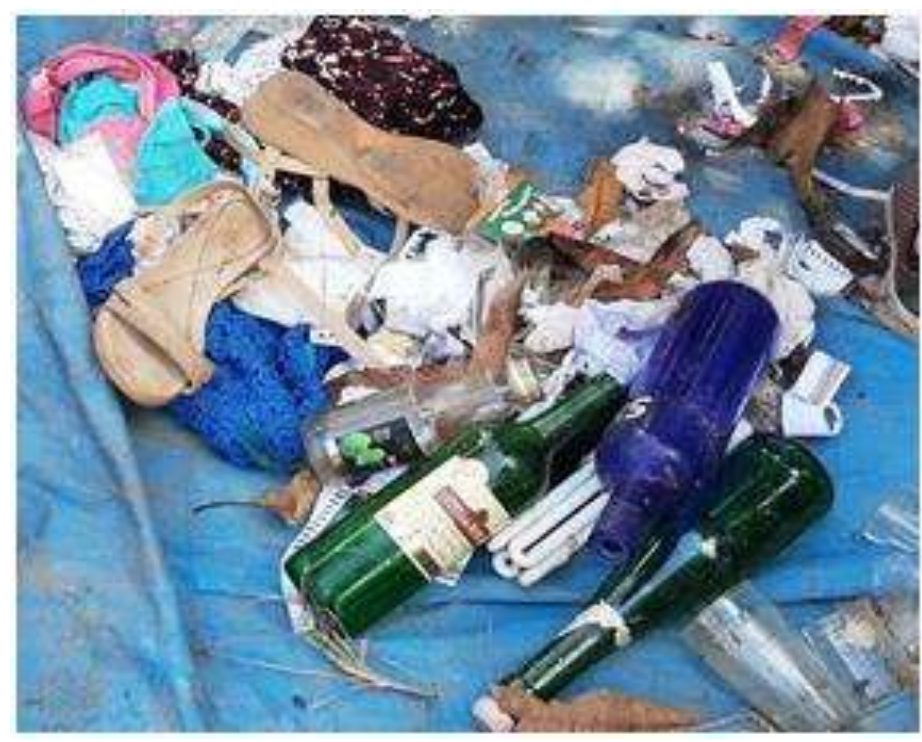

Fonte: Autores (2019).

A Figura 5 demonstra a pequena quantidade de garrafas de vidro em detrimento de roupas, calçados e demais tecidos presentes na amostra. Foram observados também copos de vidro e espelhos.

Figura 6: Resíduos orgânicos e contaminantes.

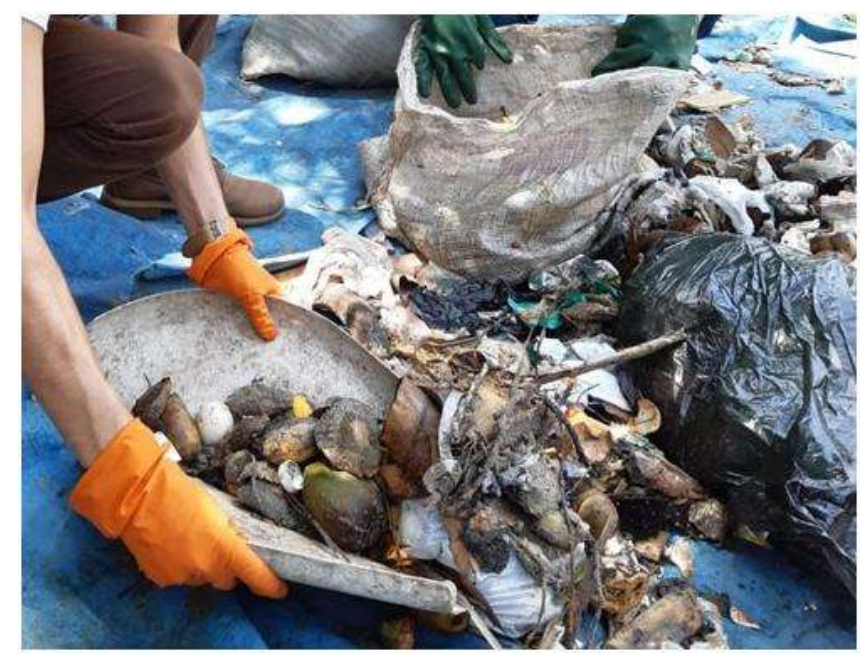

Fonte: Autores (2019).

Na Figura 6 há grande quantidade resíduos orgânicos, principalmente cascas de frutas e restos de comida, misturados com materiais com potencial reciclável.

\section{Resultados e Discussão}

\subsection{Coleta, triagem, acondicionamento e venda}

A Empresa B.A. Meio Ambiente Ltda é a responsável pelos serviços de coleta, acondicionamento e transporte dos resíduos gerados na ilha de Cotijuba, e para tal, conta com 13 funcionários (sendo três deles varredores), juntamente com ela, atua a cooperativa de catadores - Escajuba. 
De acordo com entrevistas feitas com cooperados e funcionários, a Ilha de Cotijuba produz semanalmente cerca de 1 tonelada de resíduos sólidos urbanos, coletando em média de 3 a 4 toneladas mensais, dependendo da época do ano. As coletas ocorrem três vezes por semana (segunda, quarta e sexta) para os resíduos da vila e aos finais de semana (sábado e domingo) para os resíduos da feira.

Os resíduos são transportados através de um carro coletor e destinados para um terreno com estruturas precárias para deposição dos resíduos, antigo galpão construído pela B.A., neste local é realizada atividade de separação pelos catadores. Após a separação do que pode ser comercializado, os resíduos são acondicionados em contêineres de 100 litros e colocados novamente no caminhão para embarque até o continente.

A cooperativa Escajuba existe há 16 anos e ainda não dispõe de local próprio de trabalho, nem equipamentos de proteção individual - EPI's, uniformes, luvas, máscaras, big bags e barris para acondicionamento dos resíduos, contudo, esta recebe algumas doações de EPI's da B.A. e da ARAL (Associação de Recicladores das Águas Lindas). A cooperativa realiza a triagem dos materiais a fim de coletar apenas o que é vendido para a reciclagem, e vende diretamente para à ARAL, localizada no Distrito de Icoaraci, esta por sua vez revende o material para empresas que realizam a destinação final para os resíduos recicláveis em Belém. Devido a Cooperativa ainda não estar regularizada, ela não tem contato com a venda direta.

Outra dificuldade enfrentada pela cooperativa se refere à falta de conscientização da população com relação à separação dos resíduos em suas próprias residências. Os resíduos vêm completamente misturados, prática esta que "contamina" os materiais com potencial para reciclagem e inviabiliza sua comercialização.

Pela ausência de boa infraestrutura, equipamentos e regularização as Escajuba, seus cooperados não possuem treinamentos, não realizando assim a coleta porta a porta nas residências da ilha, o que facilitaria a obter maior qualidade do material a ser vendido para reciclagem.

\subsection{Comercialização do Resíduos}

Verificou-se por meio das entrevistas realizadas com os cooperados, os valores de comercialização dos resíduos recicláveis pelas empresas ou outras cooperativas compradoras, estão expostos na Tabela 1 os preços atribuídos ao $\mathrm{kg}$ de acordo com o tipo de resíduo.

Tabela 1: Preço em reais (R\$) por quilograma $(\mathrm{kg})$ de diferentes resíduos recicláveis.

\begin{tabular}{cc}
\hline Tipo de Resíduo & $\mathbf{R} \$ / \mathbf{k g}$ \\
\hline Garrafas Pet & $\mathrm{R} \$ 1,00$ \\
\hline Garrafas de Água sanitária & $\mathrm{R} \$ 1,00$ \\
\hline Plástico Duro & $\mathrm{R} \$ 0,80$ \\
\hline Papelão & $\mathrm{R} \$ 0,80$ \\
\hline Papel Filme & $\mathrm{R} \$ 0,70$ \\
\hline Ferro & $\mathrm{R} \$ 0,38$ \\
\hline Latas de alumínio & $\mathrm{R} \$ 2,80$
\end{tabular}

Fonte: Autores (2021).

Os valores apresentados na Tabela 1 variam de $\mathrm{R} \$ 0,38$ a $\mathrm{R} \$ 2,80$, sendo quilograma do ferro e do alumínio respectivamente. Entre esses resíduos, os mais vendidos são: Garrafas Pet, de água sanitária, papel filme e papelão. E ainda de acordo com entrevista realizada, os cooperados arrecadam em média 3 toneladas de resíduos (todos os tipos juntos) mensais, resultando em uma renda em torno de $\mathrm{R} \$ 2.500,00$ (dois mil e quinhentos reais), a qual é dividida entre os 12 cooperados, de 
modo que cada cooperado recebe um valor médio de $\mathrm{R} \$ 200,00$. É válido ressaltar que esta quantidade não corresponde ao período de pico (junho-julho e dezembro-janeiro), e que na cooperativa há integrantes do mesmo grupo familiar.

Quanto aos materiais compostos de vidro, vale ressaltar que não são vendidos para a ARAL. Especificamente três tipos de vidro são vendidos para a empresa Riopel Ltda, sendo estes: garrafas de vidro branco, de vidro preto e garrafa de cerveja (1 litro) Tabela 2.

Tabela 2: Tipos de vidro com seus respectivos valores em reais (R\$) por quilograma (kg).

\begin{tabular}{cc}
\hline Tipo de Resíduo & $\mathbf{R} \mathbf{\text { kg }}$ \\
\hline Garrafa de vidro branco & $\mathrm{R} \$ 0,38$ \\
\hline Garrafa de vidro preto & $\mathrm{R} \$ 0,38$ \\
\hline Garrafa de Cerveja 1 L & $\mathrm{R} \$ 0,50$ \\
\hline
\end{tabular}

Fonte: Autores (2021).

A Tabela 2, apresenta o valor em reais do quilograma do vidro, sendo a garrafa de Cerveja de $1 \mathrm{~L}$ a com maior valor, de $\mathrm{R} \$ 0,50$. Cerca de $3 \mathrm{~m}^{3}$ de vidro, de tipos variados são vendidos diretamente para empresa duas vezes ao ano, geralmente nos meses de agosto e dezembro.

\subsection{Gravimetria dos resíduos da ilha}

A gravimetria apresentou-se como uma ferramenta auxiliadora na escolha de alternativas de caracterização, bem como no dimensionamento, pois possibilita, aliada a taxa de geração de resíduos, conhecer a estimativa da quantidade gerada por cada categoria avaliada.

Além disso, auxilia na diminuição da disposição em locais inadequados, aumentando a taxa de reaproveitamento e diminuindo, consequentemente, o nível de degradação ambiental. Contribuindo assim, para a geração de emprego e renda, devido ao potencial significativo de reciclagem, além da destinação da fração orgânica em processos de compostagem (Mesquita et al., 2020).

A composição gravimétrica identifica o percentual de cada componente em relação ao peso total da amostra de resíduos analisada. De acordo com o levantamento realizado nesta pesquisa, os principais componentes encontrados foram: matéria orgânica, contaminantes, plástico e outros, respectivamente.

Na Figura 7 está exposto o gráfico que apresenta a distribuição da caracterização gravimétrica dos resíduos sólidos urbanos da Ilha de Cotijuba. Pode ser observado que cerca de 38\% dos resíduos foram classificados como orgânicos e $62 \%$ são compostos inorgânicos. 
Figura 7: Distribuição em percentual das classes resíduos sólidos da Ilha de Cotijuba, com base na análise gravimétrica.

\section{Porcentagem de Resíduos por Classe}

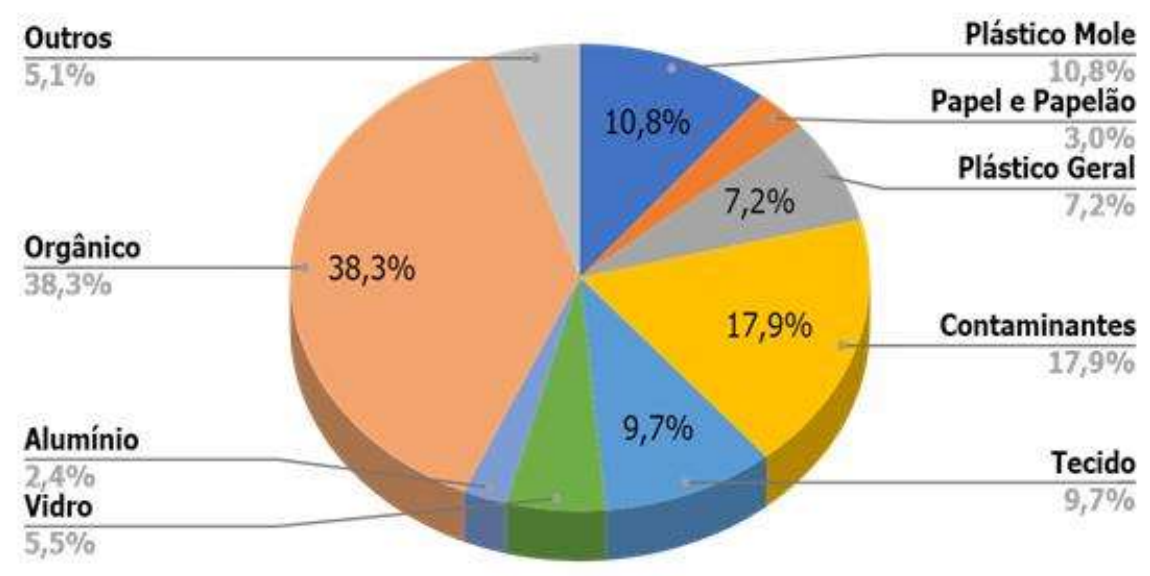

Fonte: Autores (2021).

Na Figura 7, observa-se que a fração orgânica representou 38\% do total, sendo um dos principais elementos que compõe os Resíduos Sólidos Urbanos (RSU’s) da Ilha de Cotijuba. Chama atenção, o fato de que grande parte dessa fração é composta por materiais com potencial reciclável, os quais foram descartados de maneira inadequada juntamente com restos de comida, cascas de frutas, entre outros. Devido a isso, os cooperados enfrentam grande dificuldade durante a segregação dos resíduos e isto ocorre em consequência da falta de orientação da população e/ou dos estabelecimentos quanto à destinação correta dos resíduos.

Com relação a fração inorgânica, a Figura 7, mostra que esta representa aproximadamente $29 \%$ de todo material coletado é composta por $18 \%$ de plástico, $3 \%$ de papel/papelão, 5,5\% de vidro e 2,5\% de alumínio. Os outros $33 \%$ correspondem a $18 \%$ de material contaminante, $10 \%$ de tecidos em geral e aproximadamente $5 \%$ de outros.

A ausência da segregação de resíduos apresenta grandes perdas de material com potencial reciclável, e por outro lado, gera grandes riscos aos trabalhadores das cooperativas de triagem de materiais recicláveis pelo fato de estarem em contato direto com o resíduo, e assim estarem expostos a tantos materiais, alguns perfurantes e de caráter infeccioso (Alencar et al., 2009).

Na Figura 8 observa-se o gráfico referente à proporção dos resíduos despejados pela população de Cotijuba quanto o seu potencial para reciclagem. 
Figura 8: Quantidade em porcentagem (\%) dos resíduos avaliados na análise gravimétrica, feita na Ilha de Cotijuba, quanto a sua reciclabilidade.

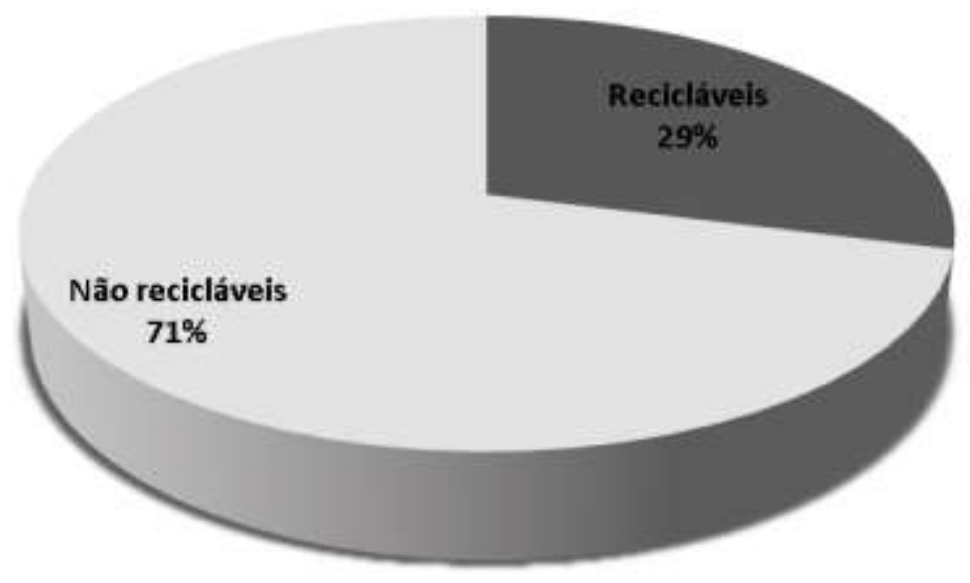

Fonte: Autores (2021).

Ainda na Figura 8, percebe-se que $71 \%$ das amostras analisadas compreenderam aos resíduos não recicláveis, refletidos nas categorias referentes aos contaminantes, tecidos, fração orgânica e outros. Já em relação aos recicláveis, observase uma proporção de $29 \%$ do total, abrangendo as categorias papel/papelão, plástico, vidro e alumínio.

Os dados observados demonstram que grande parte da população de Cotijuba não realiza a coleta seletiva na ilha, ou seja, não separa os resíduos na fonte, haja vista que tanto os recicláveis quanto não recicláveis são despejados juntos na mesma embalagem plástica em todas as amostras.

Dessa forma, infere-se que o sistema de gestão de resíduos da área de estudo apresenta-se de forma insuficiente quanto à separação dos resíduos, refletidos na ineficiência ou inexistência de campanhas de coleta seletiva e educação ambiental.

Os impeditivos considerados pela população para a realização da separação dos resíduos em casa estão relacionados com a falta de tempo, falta de conhecimento sobre como separar corretamente, falta de incentivos e falta de espaço para armazenamento. Assim, esses mesmos fatores também podem estar atrelados à população de Cotijuba quanto à separação dos resíduos na ilha. Aliado a isso, a ilha de Cotijuba é um dos pontos turístico mais requisitado durante as férias e feriados prolongados e, por apresentar grandes problemas quanto aos resíduos sólidos, este fator pode tornar-se uma limitação aos visitantes.

Em pesquisa realizada por Silva e Souza (2013) sobre a percepção ambiental dos moradores da praia do Farol, na Ilha de Cotijuba, os autores puderam perceber que cerca de 98,2\% da população local considerou o turismo, aliado a outros fatores, como um dos principais responsáveis pelo agravamento das mudanças ambientais na área. Entretanto, Sperb \& Telles (2015) enfatizam que o turismo em ilhas se apresenta como uma atividade econômica primordial para a sustentação da economia local, e que pode ser aliada às práticas de educação ambiental para um turismo sustentável quando há a aplicação de um planejamento concreto e eficaz de gestão dos resíduos sólidos.

Na Tabela 3 estão expostas as classes que compreendem os resíduos recicláveis com suas respectivas quantidades, em quilograma $(\mathrm{kg})$ e porcentagem $(\%)$, obtidos na análise gravimétrica. 
Tabela 3: Classes que apresentam potencial para reciclagem e reutilização.

\begin{tabular}{ccc}
\hline Classe & Peso $(\mathbf{k g})$ & \% \\
\hline Plástico Mole / Sacos & 6,26 & 37,23 \\
Papel / Papelão & 1,73 & 10,29 \\
Plástico Geral & 4,2 & 24,98 \\
Vidro & 3,20 & 19,06 \\
Alumínio & 1,42 & 8,44 \\
\hline Total & 16,81 & 100,00 \\
\hline \multicolumn{2}{c}{ Fonte: Autores $(2021)}$.
\end{tabular}

Ao observar a Tabela 3, nota-se uma ordem decrescente de Classes avaliadas por porcentagem, a começar por Plástico Mole, Plástico Geral, Vidro, Papelão e Alumínio, que juntos correspondem a 16,81 kg, Uma quantidade bem inferior ao total de material coletado na Ilha, referente especificamente a somente $29 \%$ do material total como mostrado na Figura 8.

De acordo com a PNRS, os materiais com potencial reciclável são aqueles que apresentam características relacionadas à possibilidade de serem submetidos a processos de transformação, os quais envolvem a alteração de suas propriedades físicas, químicas e biológicas. Tais processos objetivam a reinserção desses materiais no ciclo do processo produtivo, seja como novos insumos ou novos produtos.

De acordo com o panorama sobre os resíduos sólidos urbanos do Brasil, a região norte é a que menos coleta os resíduos gerados, apesar de ser a terceira região com a maior quantidade de municípios que possuem iniciativas de coleta seletiva. Além disso, a região Norte é a segunda que mais direciona os seus resíduos sólidos para lixões a céu aberto (ABRELPE, 2019).

Tal problemática pode ser consequência da insuficiência de recursos destinados à gestão dos resíduos sólidos na região. De acordo com a Associação Brasileira de Empresas de Limpeza Pública e Resíduos Especiais (ABRELPE, 2019) no ano de 2017 foram aplicados 697 milhões de reais para a gestão dos RSU na região norte, enquanto para a região sudeste foram destinados 5.343 milhões de reais, haja vista que a região sudeste é a que mais destina seus RSU para aterros sanitários e controlados. Na Figura 9 tem-se a comparação da Análise gravimétrica feita para o Brasil e para a Ilha de Cotijuba em 2019. 
Figura 9: Disposição dos tipos de resíduos coletados no Brasil em 2019 (ABRELPE, 2020) e na Ilha de Cotijuba no mesmo ano.

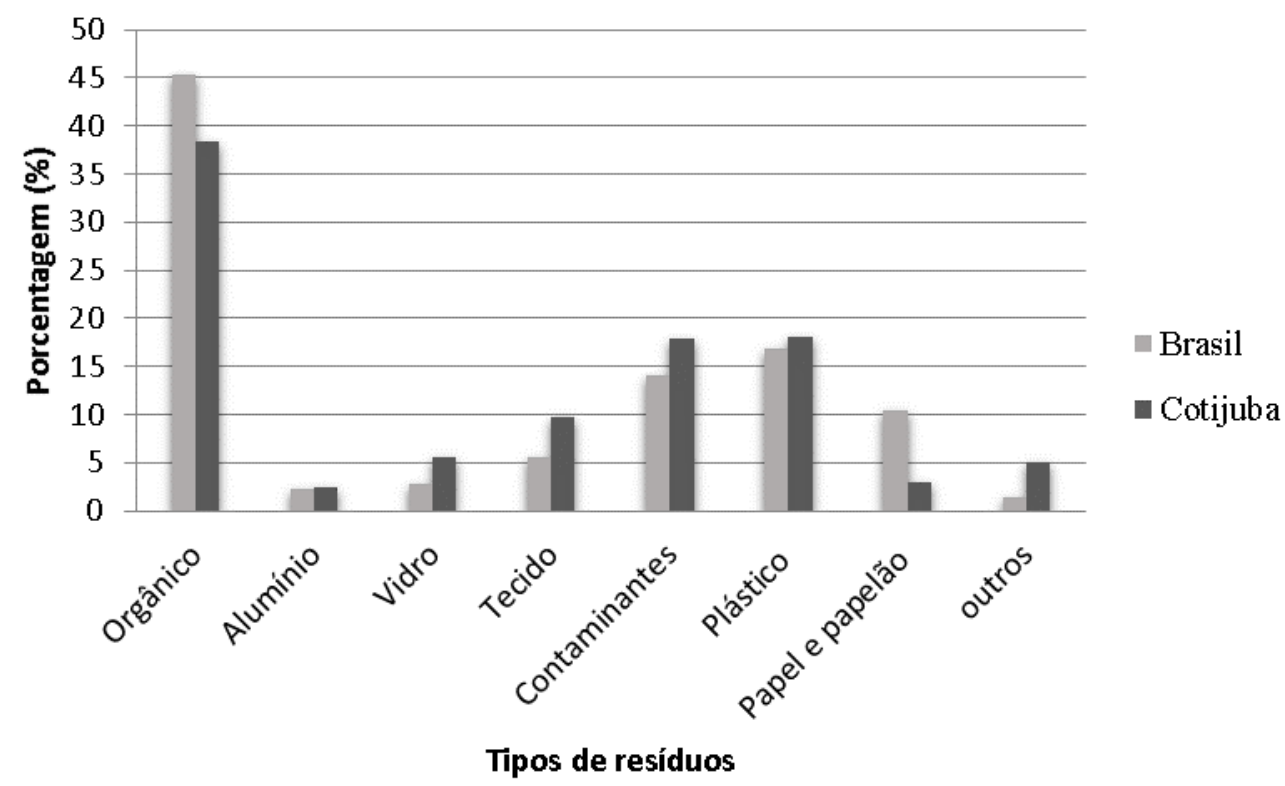

Fonte: Autores (2021).

Ao observar a Figura 9, percebe-se que a dinâmica de disposição dos tipos de resíduos presentes na Ilha de Cotijuba obedeceu à tendência nacional. Apenas para a categoria "papel e papelão" houve uma discrepância notável, em que a média nacional apresentou cerca de $10 \%$, e para a Ilha de Cotijuba menos que 5\%.

Este dado pode estar relacionado ao fato de que os resíduos não são separados na em seco e úmido na ilha. E ao misturar, o papel e o papelão são os que mais se "contaminam” com o material orgânico, deixando de ser material reciclável para se configurarem como rejeito.

Desta forma, nota-se a importância da educação ambiental em orientar a segregação dos resíduos e incentivar a coleta seletiva, que por sua vez configura-se em uma das alternativas para a solução de parte do problema da destinação correta dos resíduos sólidos urbanos, por possibilitar o melhor reaproveitamento dos materiais recicláveis e da matéria orgânica para a comunidade local (Coutinho, 2020).

\section{Considerações Finais}

A Ilha de Cotijuba se destaca por ser um importante ponto turístico, em contra partida esse fato gera grande problemática ambiental local, uma vez que a Ilha apresenta considerável quantidade e tipos de resíduos em sua extensão, tornando-se um potencial gerador de RSU. Logo, tomadas de decisões relativas ao melhor planejamento e gerenciamento dos resíduos na Ilha de Cotijuba, são necessários, principalmente aquelas que estão diretamente relacionados a destinação correta, passando por triagem, segregação e transporte dos resíduos.

A intensificação de políticas públicas direcionadas à educação ambiental, voltadas principalmente ao reaproveitamento, reciclagem auxiliariam de maneira eficaz esse processo. $\mathrm{Na}$ Ilha, a implantação da coleta seletiva porta a porta também faria diferença, sendo esta, a maneira mais eficaz para a cooperativa arrecadar o maior número de material com potencial para venda e consequente geração de renda aos cooperados.

O incentivo de parcerias com instituições de ensino e pesquisa, auxiliariam tanto em projetos de educação ambiental como nos estudos de composição gravimétrica a fim de que haja maior caracterização dos resíduos da Ilha, para que assim, a 
política de gestão de resíduos sólidos utilizada atualmente seja adaptada para a realidade da Ilha, uma vez que é insustentável do ponto de vista socioambiental.

Além disso, com esta pesquisa observa-se a necessidade de estudos futuros que abordem essa temática na área, visando identificar e quantificar os tipos de resíduos que são descartados pelos turistas em época de veraneio, e realizar comparação entre os meses de maior e menor visitação na Ilha, observar essa diferença para assim promover gestão eficaz dos RSU durante todo o ano.

\section{Referências}

ABRELPE. (2019). Panorama dos resíduos sólidos no Brasil. Associação Brasileira de Empresas de Limpeza Pública e Resíduos Especiais. https://abrelpe.org.br/panorama/.

Barbosa, A. S. \& Gonçalves, R. M. R. (2018). Resíduos urbanos: impactos socioambientais dos lixões a céu aberto. Projectus. 3 (3), 1-15. https://doi.org/10.15202/25254146.2018v3n3p1.

BelémTur. (2008). Plano diretor da Ilha de Cotijuba. Belém, Pará. Secretaria Municipal de Coordenação Geral do Planejamento e Gestão, Companhia de Desenvolvimento Metropolitano e Secretaria de Urbanismo (BELÉMTUR). http://www.belem.pa.gov.br/.

Bello, L. A. L. \& Huffner, P. J. G. (2012). Análise dos impactos ambientais da expansão urbana na Ilha de Cotijuba, Belém-PA. Revista Caminhos de Geografia, 13(44), 286-298. http://www.seer.ufu.br/index.php/caminhosdegeografia/.

Brasil. (2010). Lei $n^{\circ}$ 12.305, de 2 de agosto de 2010. Institui a Política Nacional de Resíduos Sólidos; altera a Lei nº 9.605 , de 12 de fevereiro de 1998; e dá outras providências. Diário Oficial da República Federativa do Brasil, Brasília.

Brilho, S. S. Q. C. (2015). Dinâmica Econômica e Social na Amazônia Rural: o Protagonismo do Movimento de Mulheres das Ilhas de Belém - MMIB (PA). Tese de Doutorado em Engenharia Agrícola - Universidade Estadual de Campinas, Campinas.

Casais, A. G. M., Silva, C. A. Q., Cruz, L. M. C. \& Silveira, R. N. P. O. (2020). Análise quantiqualitativa da gestão de resíduos sólidos na cidade de PalmasTO: um foco na coleta seletiva e ODS. IBEAS - Instituto Brasileiro de Estudos Ambientais. Anais. III Congresso Sul - Americano de Resíduos Sólidos e Sustentabilidade. Gramado/RS.

CTBEL. (1999). Pesquisa da linha Fluvial Belém - Icoarací - Cotijuba - Icoarací - Belém (1997 e 1999). Companhia de transporte do Município de Belém (CTBEL).

CTBEL. (2005). Relatório técnico, 2005. Companhia de Transportes de Belém (CTBEL). Belém em Ação. http://www.belem.pa.gov.br/segep/cmb2005/IICMB_Rel_final.pdf .

Coutinho, M. L. (2020). Revisão da literatura: fração orgânica dos resíduos sólidos urbanos, impactos em aterros sanitários e compostagem como solução. Trabalho de Curso de Engenharia Ambiental e Sanitária da Universidade Federal de Juiz de Fora.

Silva, T. S. N. \& Souza, C. F. (2013). Percepção dos impactos do Turismo pelos moradores da Praia do Farol-Ilha de Cotijuba/PA. Revista Brasileira de Gestão e Desenvolvimento Regional, 9(1), 262-280. http://www.ibeas.org.br/conresol/conresol2020/IV-014.pdf

Alencar, M. C. B.; Orlandini, C. C. \& Cardoso, M. C. A. (2009). Condições de trabalho e sintomas relacionados à saúde de catadores de materiais recicláveis em Curitiba. Revista Terapia Ocupacional. São Paulo, 20(1), 36-42. https://doi.org/10.11606/issn.2238-6149.v20i1p36-42.

Diário do Turismo (2016) - https://diariodoturismo.com.br/cotijuba-uma-ilha-paraiso-para-quem-busca-sombra-e-agua-fresca/.

Fontão, S. S. (2020). A importância da associação de catadores de materiais recicláveis: o contexto social dos catadores. Universidade Federal de ViçosaUFV. 20(72). http://revistaea.org/artigo.php?idartigo=3997.

Franco, C.S. (2012). Caracterização gravimétrica dos resíduos sólidos domiciliares e percepção dos hábitos de descarte no sul de Minas Gerais. Dissertação de Mestrado em Recursos Hídricos em Sistemas Agrícolas. Universidade Federal de Lavras, Lavras.

Gasques, A. C. F. (2013). Caracterização quantitativa e gravimétrica dos resíduos sólidos urbanos do município de Campo Mourão - PR. Trabalho de Conclusão de Curso de Engenharia Ambiental - Universidade Tecnológica Federal do Paraná, Campo Mourão, 54p.

Gouveia, N. (2012). Resíduos sólidos urbanos: impactos socioambientais e perspectiva de manejo sustentável com inclusão social. Ciência \& Saúde Coletiva, 17(6):1503-1510. https://doi.org/10.1590/S1413-81232012000600014.

Huffner, J. G. P. \& Bello, L. A. L. (2013). Turismo e indicadores de sustentabilidade ambiental na ilha de Cotijuba. Revistaea. 20(46). http://www.revistaea.org/artigo.php?idartigo=1685.

Lima, P. G., Destro, G. E., Braga, S. S. \& Forti, J. C. (2018). Análise gravimétrica dos resíduos sólidos urbanos de um aterro sanitário. Revista Brasileira de Engenharia de Biossistemas, 12(4), 410-426. https://doi.org/10.18011/bioeng2018v12n4p410-426.

Meireles, J. F. (2019). Espaços educadores sustentáveis: a inserção da educação ambiental na Associação dos Recicladores Ambientais de Mundo Novo/MS. Dissertação Pós-Graduação em Ciências Ambientais da Universidade Estadual do Oeste do Paraná, Unioeste/Campus. 
Research, Society and Development, v. 10, n. 12, e435101220724, 2021

(CC BY 4.0) | ISSN 2525-3409 | DOI: http://dx.doi.org/10.33448/rsd-v10i12.20724

Melo, O. C. (2010). A comunidade e a construção do lugar na Ilha de Cotijuba (PA). Dissertação (Mestrado em Geografia) - Universidade Federal do Pará, Belém, 1-192.

Menezes, R. O., Castro, S. R., Silva, J. B. G., Texeira, G. P. \& Silva, M. A. M. (2019). Análise estatística da caracterização gravimétrica de resíduos sólidos domiciliares: estudo de caso do município de Juiz de Fora, Minas Gerais. Revista Eng. Sanit. Ambient. 24(2), 271-282. DOI: 10.1590/S1413-41522019177437.

Mesquita, T. O. \& Da Silva, C.N. (2010). Turismo na Amazônia ribeirinha: um estudo sobre as repercussões sócio-espaciais da atividade turística na ilha de Cotijuba, Belém - Pará. Encontro nacional da Anppas. Florianópolis.

Moura, A. A., Lima, W. Sc. \& Do Rocio Archanjo, C. R. (2012). Análise da composição gravimétrica de resíduos sólidos urbanos: estudo de caso-município de Itaúna-MG. SYNTHESIS| Revistal Digital FAPAM, 3(1), 4-16.

PARATUR. (2011). Companhia Paraense de Turismo. Governo do Pará. Belém, Pará. http://www.paratur.com.br/portal/turismo-no-norte/ilhade-cotijubabelem-pa/

Pereira, N. S. S. (2019). Metropolização e turismo: um estudo sobre a Ilha de Cotijuba, Belém - Pará. Paper do NAEA, 28(3), 452.

Pereira, A. S., Shitsuka, D. M., Parreira, F. J., Shitsuka, R. (2018). Metodologia da pesquisa científica. https://repositorio.ufsm.br/bitstream/handle/1/158 24/Lic_Computacao_Metodologia-Pesquisa-Cientifica.pdf?sequence=1.

Rezende, J. H. (2013). Composição gravimétrica e peso específico dos resíduos sólidos urbanos em Jaú (SP). Engenharia Sanitária e Ambiental, 18 (1), 1-8.

Rodrigues, K. S., Chaves, A. A. S., Lopes, M. D. S. B., Oliveira cunha, M. V. P., Lopes, D. F. \& Carrera, V. M. (2020). O nível de sustentabilidade no gerenciamento de resíduos sólidos na ilha de Cotijuba-PA. Research, Society and Development, 9(10). http://dx.doi.org/10.33448/rsd-v9i10.8883.

Santos, T. V. (2017). Metropolização e diferenciações regionais: estruturas intraurbanas e dinâmicas metropolitanas em Belém e Manaus. Cad. Metrop. [online]. 19(40), 865-890. https://doi.org/10.1590/2236-9996.2017-4008.

Sperb, M. P. \& Telles, D. H. Q. (2015). Gestão de Resíduos Sólidos e Turismo: O Tratamento Dado por Meios de Hospedagem e Pelo Setor Público na Ilha do Mel, PR. Rosa dos Ventos-Turismo e Hospitalidade, 6(4), 603-622. 